\title{
Positive Symptoms in Antipsychotic-naïve Schizophrenia are Associated with Increased Body Mass Index after Treatment
}

\author{
Shih-Hsien Lin ${ }^{1,2}$, Huai-Hsuan Tseng ${ }^{1,2}$, Hsin Chun Tsai ${ }^{1,3}$, Mei Hung Chi ${ }^{1}$, I Hui Lee', Po See Chen ${ }^{1,2,3}$, \\ Kao Chin Chen ${ }^{1}$, Yen Kuang Yang ${ }^{1,2,4}$ \\ ${ }^{1}$ Department of Psychiatry, National Cheng Kung University Hospital, College of Medicine, National Cheng Kung University, ${ }^{2}$ Institute of \\ Behavioral Medicine, College of Medicine, National Cheng Kung University, Tainan, ${ }^{3}$ Department of Psychiatry, National Cheng Kung University \\ Hospital, Dou-Liou Branch, Yunlin, ${ }^{4}$ Department of Psychiatry, Tainan Hospital, Ministry of Health and Welfare, Tainan, Taiwan
}

\begin{abstract}
Objective: Weight gain is an important risk factor for morbidity and mortality among patients with schizophrenia. We speculated that positive symptoms, related to dopaminergic hyperactivity and altered mesolimbic function, are associated with weight gain.

Methods: Twenty-two antipsychotic-naïve, first-episode patients with schizophrenia were enrolled. The Positive and Negative Syndrome Scale was completed at enrollment and follow-up. Body mass index (BMI) was also measured. Results: The increase in BMI, after $6.04 \pm 2.16$ years of follow-up, was associated with positive symptoms, but not negative symptoms, before treatment with antipsychotics in antipsychotic-naïve patients with schizophrenia.

Conclusion: This finding implied that dopaminergic hyperactivity could be an important factor to predict the treatment outcome. Body weight control is important for the health management of patients with schizophrenia with more severe positive symptoms.
\end{abstract}

KEY WORDS: Mesolimbic pathway; Metabolic syndrome; Positive syndrome; Schizophrenia; Weight gain.

\section{INTRODUCTION}

Altered dopaminergic activity of $\mathrm{D}_{2}$ receptors in the mesolimbic pathway has been proposed as a neural mechanism of positive symptoms, one of the core features of schizophrenia [1-3]. $\mathrm{D}_{2}$ receptor occupancy is predictive of treatment response, and side effects may occur $[4,5]$.

Weight gain is an important side effect that may be induced by antipsychotic treatment [6,7]. An association has been found between treatment response and weight gain [8-10]. These findings implied that mesolimbic dopamine function may play an important role in weight gain among patients with schizophrenia.

Alternatively, changes in the dopamine system, which

Received: October 1, 2019 / Revised: March 4, 2020

Accepted: May 26, 2020

Address for correspondence: Yen Kuang Yang

Department of Psychiatry, National Cheng Kung University

Hospital, 138 Sheng Li Road, North Dist., Tainan 70403, Taiwan

E-mail: ykyang@mail.ncku.edu.tw

ORCID: https://orcid.org/0000-0001-9355-9636 is critical to the reward pathway function, might explain weight gain in schizophrenia [11]. Evidence has shown that activity at the dorsal striatum, during reward-related tasks at baseline is predictive of weight gain after 6 weeks of treatment with amisulpride [12].

It is likely that positive symptoms could be related to weight gain after antipsychotic treatment. However, evidence is very scarce. Results from The Clinical Antipsychotic Trials of Intervention Effectiveness (CATIE) schizophrenia trial indicated that symptom reduction and the Positive and Negative Syndrome Scale (PANSS) total score were related to an elevated body mass index (BMI) within 18 months [13]. Meanwhile, the relationship between negative symptoms and body weight is unclear [14].

We hypothesized that more severe positive symptoms before treatment would be associated with greater weight gain after treatment. The associations between negative symptoms and weight gain were also probed in this study.

The present study aimed to examine these associations in antipsychotic-naïve patients with schizophrenia.

(c) This is an Open-Access article distributed under the terms of the Creative Commons Attribution Non-Commercial License (http://creativecommons.org/licenses/by-nc/4.0) which permits unrestricted non-commercial use, distribution, and reproduction in any medium, provided the original work is properly cited. 


\section{METHODS}

\section{Subjects}

The study was conducted in the department of psychiatry in the medical center at southern Taiwan. The setting of the recruitment included the psychiatric inpatient acute ward, daycare ward and outpatient department. The research protocol was approved by a local ethical committee of National Cheng Kung University Hospital (no. A-BR-103-017), and written informed consent was obtained from each subject. The inclusion criteria were:

1. Patients must fulfill the Diagnostic and Statistical Manual of Mental Disorders, Fourth Edition (DSM-IV) criteria, and were diagnosed and interviewed by experienced psychiatrists who have been practicing for more than 5 years.

2. Aged between 18 and 65 years.

3. No physical illness with stable vital signs and no evidence of substance abuse/dependence as assessed during the clinical interview with the research psychiatrist at the time of enrollment.

4. Never received any antipsychotic or antidepressant treatment and was free of any psychotropic medication at the time of testing.

5. The patient or their legal caregiver had signed an informed consent document, indicating that they understood the purpose and procedures of the study.

Patients with other co-morbid psychiatric illnesses, substance abuse/dependence, neurological illnesses, mental retardation, at risk of suicide/harming, pregnant (or suspected to be), or not suitable to enter this study were excluded.

Twenty-two antipsychotic-naïve, first-episode patients with schizophrenia $(13$ males, 9 females, age $=27.60 \pm$ 8.31 years) were included. The mean duration of illness was $4.81 \pm 6.64$ years. The participants overlapped with those included in our previous studies $[15,16]$. The average length of follow-up was $6.04 \pm 2.16$ years.

\section{Measures}

BMI was calculated The PANSS (score range 30-210 from least to most symptomatic) [17] was used to measure positive and negative symptoms. These measures were conducted before treatment, and at the follow-up visit.

\section{Statistics}

Correlation analysis was used test the hypothesis and examine the associations between BMl and symptoms. Multiple regression analyses were used to assess the associations with increased BMl as outcome variables and positive symptoms at baseline as predicting variables, after controlling the potential confounders, duration of illness and length of follow-up, as well as sex and age, in a series of adjusted models. We also conducted this analysis with antipsychotic dose (CPZ-equivalent dose) as confounder. However, the sample size with reliable dosage data is small $(n=17)$. A set of generalized linear model were used as supplemental analysis. Statistical significance was established at $p<0.05$. SPSS version 17 (SPSS Inc., Chicago, IL, USA) was used for all analyses.

\section{RESULTS}

\section{Symptoms and BMI Before and After Treatment}

The positive and negative symptoms improved and BMI increased after treatment, as shown in Table 1. BMI was not associated with positive symptoms (baseline: $r=-0.23$, $p=0.30$; follow-up: $r=0.28, p=0.21$ ) or negative symptoms (baseline: $r=0.25, p=0.25$; follow-up: $r=0.13, p=$ $0.56)$ at baseline or follow-up. In addition, no significant associations were found between the increase in $\mathrm{BMI}$ and improvement of positive $(r=0.28, p=0.21)$ or negative symptoms $(r=0.36, p=0.10)$.

\section{The Hypothesis Testing}

The increase in BMI was calculated (BMI at follow-up$\mathrm{BMI}$ at baseline). This increase was associated with the

Table 1. PANSS scores and BMI at baseline and after treatment (paired $t$ test) among 22 patients with schizophrenia

\begin{tabular}{llll}
\hline \multirow{2}{*}{ Variable } & Baseline & After treatment & Statistic \\
\cline { 4 - 4 } & & & $t$ \\
\hline Positive scale & $22.59 \pm 6.14$ & $13.18 \pm 5.13$ & $7.75^{* *}$ \\
Negative scale & $22.59 \pm 9.00$ & $17.27 \pm 5.10$ & $3.70^{* *}$ \\
General scale & $42.50 \pm 13.90$ & $26.23 \pm 8.57$ & $5.88^{* *}$ \\
Total & $87.68 \pm 25.43$ & $56.68 \pm 17.06$ & $6.58^{* *}$ \\
GAF & $36.27 \pm 11.91$ & $60.27 \pm 12.43$ & $8.05^{* *}$ \\
BMI & $21.61 \pm 3.91$ & $25.74 \pm 4.89$ & $4.99^{* *}$ \\
\hline
\end{tabular}

Values are presented as mean \pm standard deviation. Thirteen males and 9 females were included, age $=27.60 \pm 8.31$ years .

PANSS, Positive and Negative Syndrome Scale; BMI, body mass index; GAF, Global Assessment of Function. ** $p<0.01$ 

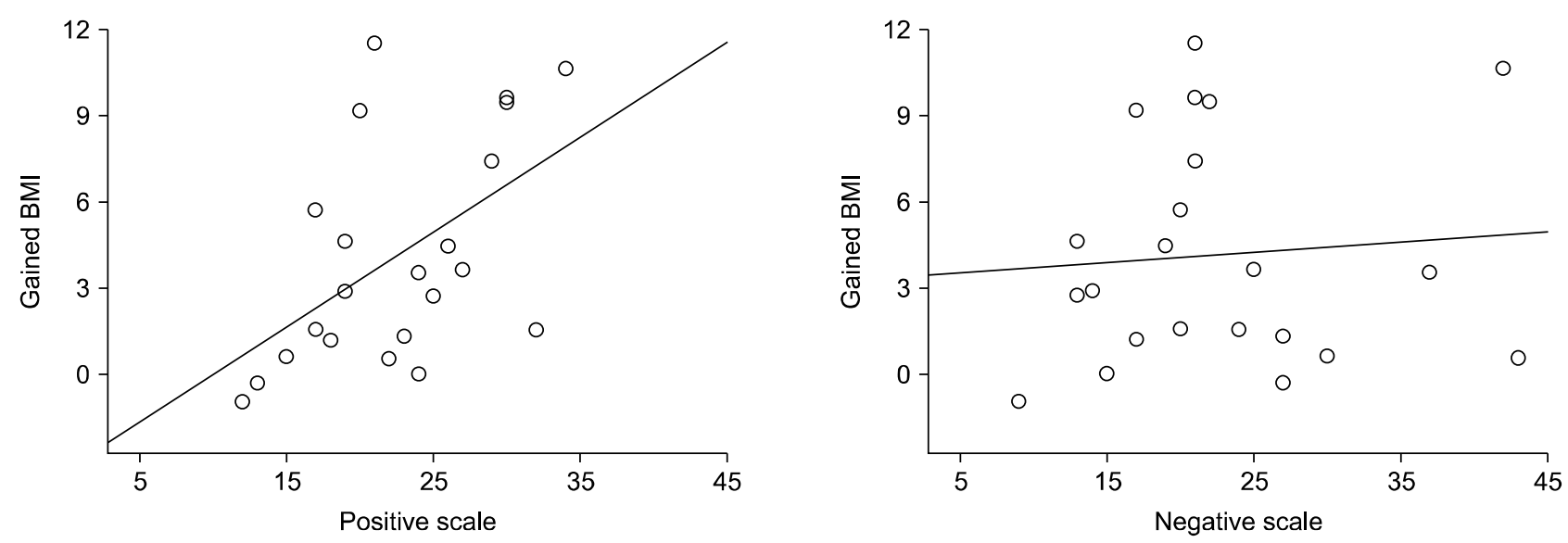

Fig. 1. Increase in BMI was associated with the PANSS positive scale score $(r=0.52, p<0.05)$ but not the PANSS negative scale score $(r=0.05$, not significant).

BMI, body mass index; PANSS, Positive and Negative Syndrome Scale.

positive subscale score at baseline $(r=0.52, p<0.05)$, but not with the negative subscale score at baseline $(r=$ 0.09, not significant [N.S.]), as shown in Figure 1. No associations were found between BMI and positive and negative symptoms at follow-up. A generalized linear model analysis confirmed that the $\mathrm{BMI}$ at follow-up is both related baseline $\mathrm{BMI}\left(\mathrm{B}=0.04, \mathrm{SE}=0.01\right.$, Wald $\chi^{2}=16.07$, $p<0.001)$, and positive subscale $(\mathrm{B}=0.014$, $\mathrm{SE}=0.006$, Wald $\chi^{2}=4.22, p=0.04$ ).

\section{Sensitivity Analysis with Potential Confounders}

A generalized linear model analysis confirmed that the $\mathrm{BMI}$ at follow-up is related with positive subscale score at baseline robustly $\left(\mathrm{B}=0.14, \mathrm{SE}=0.005\right.$, Wald $\chi^{2}=7.82, p<$ $0.01)$, after controlling the effects of $\mathrm{BMI}$ at baseline $(\mathrm{B}=$ $0.04, \mathrm{SE}=0.01$, Wald $\left.\chi^{2}=14.63, p<0.01\right)$, age $(\mathrm{B}=-$ $0.004, \mathrm{SE}=0.005$, Wald $\chi^{2}=0.60$, N.S. $), \operatorname{sex}(\mathrm{B}=-0.04, \mathrm{SE}=$ 0.06 , Wald $\chi^{2}=0.32$, N.S.), duration of illness $(B=-0.004$, $\mathrm{SE}=0.005$, Wald $\chi^{2}=0.51$, N.S.), and length of follow-up $\left(\mathrm{B}=0.04, \mathrm{SE}=0.02\right.$, Wald $\left.\chi^{2}=5.54, p<0.05\right)$.

We also analysis the dose of anti-psychotic as a confounder in the sample with reliable data $(n=17)$ with generalized linear model. The association between positive scale is significant $\left(\mathrm{B}=0.01, \mathrm{SE}=0.05\right.$, Wald $\chi^{2}=4.52, p<$ $0.05)$, after including the effect of $C P Z$ equivalent dose $(B=$ $0.000, \mathrm{SE}=0.0001$, Wald $\chi^{2}=1.77$, N.S. $), \mathrm{BMI}(\mathrm{B}=0.03$, $\mathrm{SE}=0.01$, Wald $\left.\chi^{2}=14.34, p<0.01\right)$ at baseline and duration of illness $\left(\mathrm{B}=0.04, \mathrm{SE}=0.02\right.$, Wald $\chi^{2}=4.68, p=$ 0.03). The correlation analysis indicated that CPZ equivalent dose is not related with positive $(r=0.33, p=0.20)$ nor negative $(r=-0.14$, N.S.) score.

\section{DISCUSSION}

Robust positive associations between positive symptoms at the antipsychotic-naïve stage before treatment and the increase in BMl after long-term treatment were observed in patients with schizophrenia. To the best of our knowledge, our findings were novel in terms of the long-term follow-up study design in an antipsychotic-naïve cohort [13]. As the time taken to reach a plateau of weight gain can be up to several months, and weight gain may continue for a few years $[18,19]$, the design of our study may help to clarify the role of symptoms before treatment in long-term prognosis.

It has been proposed that schizophrenia can be classified into two distinct subtypes, hyperdopaminergic (type A) and normodopaminergic (type B) [3]. Considering initial positive symptoms as a manifestation of hyperdopaminergic activity (especially the $\mathrm{D}_{2}$ receptor) [1], and taking elevated $\mathrm{BMI}$ as a marker of treatment response [8-10], the observed association between most severe initial positive symptoms and BMI increase over time implied a link of initial hyperdopaminergia with a better treatment response. Our findings were in agreement with the fact that dopamine tone before treatment is predictive of prognosis after antipsychotic treatment [16]. Our findings could be evidence in support of a role of dopaminergic activity in subtyping of schizophrenia $[3,16]$. Also, the direction of the association between the increase 
in BMI and improvement of positive symptoms $(r=0.28, p$ $=0.21$ ) was in agreement with previous findings [8].

Positive symptoms are related to mesolimbic pathway dysfunction, which is an important mechanism in addiction [20,21]. Recently, the role of this mechanism was noted as one explanation for weight gain in schizophrenia, as the biological basis for this problematic phenomenon is as yet unclear $[11,12]$. Although our finding did not confirm the role of negative symptoms and BMI, it is worth to note that recent study elucidated that negative symptoms (anhedonia and asociality) is related with higher BMI among patients received olanzapine- or clozapine-treatment [22]. The association between BMI change, and different domains of negative symptoms, remains to be probed.

Several limitations should be noted. First, the study was naturalistic, and hence the treatment and length of follow-up varied between patients. Second, the sample size was small and lack of statistical power. Also, the power to confirm association between $\mathrm{CPZ}$ dosage and BMI, could be limited due to type II error, caused by small sample size. Third, the dopaminergic function of the patients is not controlled. Fourth, although we employed several potential confounders in sensitivity to testing the robustness of our finding. These variables are not comprehensive.

\section{- Acknowledgments}

This research was funded by the National Science Council of Taiwan (NSC 95-2314-B-006-052 and NSC 99-2314-B-006-019-MY3), the Atomic Energy Council of Taiwan (NSC 91-NU-7-006-002), and the Ministry of Science and Technology, R.O.C. (MOST 104-2314-B006-032-MY2). The authors thank Mr. Chien Ting Lin for his administrative support. The funding institutions of this study had no further role in the study design, the collection, analysis and interpretation of data, the writing of this paper, or the decision to submit for publication.

\section{Conflicts of Interest}

No potential conflict of interest relevant to this article was reported.

\section{- Author Contributions}

Conceptualization: Yen Kuang Yang, Study design: Kao Chin Chen, Data acquisition: Hsin Chun Tsai, Mei Hung Chi, I Hui Lee, Kao Chin Chen, and Yen Kuang Yang,
Formal analysis: Huai-Hsuan Tseng and Po See Chen, Writing-original draft: Shih-Hsien Lin. All authors interpreted the analysis of the results and helped to revise the manuscript. All authors interpreted the analysis of the results and helped to revise the manuscript.

\section{ORCID}

Shih-Hsien Lin https://orcid.org/0000-0001-9904-8300 Huai-Hsuan Tseng https://orcid.org/0000-0002-5213-1585 Hsin Chun Tsai https://orcid.org/0000-0002-9032-5006 Mei Hung Chi https://orcid.org/0000-0001-5408-5466 I Hui Lee https://orcid.org/0000-0003-2970-5744 Po See Chen https://orcid.org/0000-0003-4963-578X Kao Chin Chen https://orcid.org/0000-0001-8091-8820 Yen Kuang Yang https://orcid.org/0000-0001-9355-9636

\section{REFERENCES}

1. Brisch R, Saniotis A, Wolf R, Bielau H, Bernstein HG, Steiner $\mathrm{J}$, et al. The role of dopamine in schizophrenia from a neurobiological and evolutionary perspective: old fashioned, but still in vogue. Front Psychiatry 2014;5:47.

2. de Greef R, Maloney A, Olsson-Gisleskog P, Schoemaker J, Panagides J. Dopamine $D_{2}$ occupancy as a biomarker for antipsychotics: quantifying the relationship with efficacy and extrapyramidal symptoms. AAPS J 2011;13:121-130.

3. Howes OD, Kapur S. A neurobiological hypothesis for the classification of schizophrenia: type $A$ (hyperdopaminergic) and type B (normodopaminergic). Br J Psychiatry 2014;205:1-3.

4. Kapur S, Zipursky R, Jones C, Remington G, Houle S. Relationship between dopamine $D_{2}$ occupancy, clinical response, and side effects: a double-blind PET study of first-episode schizophrenia. Am J Psychiatry 2000;157:514-520.

5. Howes OD, Egerton A, Allan V, McGuire P, Stokes P, Kapur S. Mechanisms underlying psychosis and antipsychotic treatment response in schizophrenia: insights from PET and SPECT imaging. Curr Pharm Des 2009;15:2550-2559.

6. Baptista T. Body weight gain induced by antipsychotic drugs. mechanisms and management. Acta Psychiatr Scand 1999; 100:3-16

7. Manu P, Dima L, Shulman M, Vancampfort D, De Hert M, Correll CU. Weight gain and obesity in schizophrenia: epidemiology, pathobiology, and management. Acta Psychiatr Scand 2015;132:97-108.

8. Bai YM, Lin CC, Chen JY, Lin CY, Su TP, Chou P. Association of initial antipsychotic response to clozapine and long-term weight gain. Am J Psychiatry 2006;163:1276-1279.

9. Czobor P, Volavka J, Sheitman B, Lindenmayer JP, Citrome L, McEvoy J, et al. Antipsychotic-induced weight gain and therapeutic response: a differential association. J Clin Psychopharmacol 2002;22:244-251.

10. Ascher-Svanum H, Stensland M, Zhao Z, Kinon BJ. Acute 
weight gain, gender, and therapeutic response to antipsychotics in the treatment of patients with schizophrenia. BMC Psychiatry 2005;5:3.

11. Grimm O, Kaiser S, Plichta MM, Tobler PN. Altered reward anticipation: potential explanation for weight gain in schizophrenia? Neurosci Biobehav Rev 2017;75:91-103.

12. Nielsen MØ, Rostrup E, Wulff S, Glenthøj B, Ebdrup BH. Striatal reward activity and antipsychotic-associated weight change in patients with schizophrenia undergoing initial treatment. JAMA Psychiatry 2016;73:121-128.

13. Hermes E, Nasrallah H, Davis V, Meyer J, McEvoy J, Goff D, et al. The association between weight change and symptom reduction in the CATIE schizophrenia trial. Schizophr Res 2011;128:166-170.

14. Koga M, Nakayama K. Body weight gain induced by a newer antipsychotic agent reversed as negative symptoms improved. Acta Psychiatr Scand 2005;112:75-76; discussion 77.

15. Tseng HH, Chen KC, Chen PS, Lee IH, Chang WH, Yao WJ, et al. Dopamine transporter availability in drug-naïve patients with schizophrenia and later psychotic symptoms severity. Schizophr Res 2017;190:185-186.

16. Yang YK, Yu L, Yeh TL, Chiu NT, Chen PS, Lee IH; SPECT study. Associated alterations of striatal dopamine $D_{2} / D_{3}$ receptor and transporter binding in drug-naive patients with schizophrenia: a dual-isotope SPECT study. Am J Psychiatry 2004;161:1496-1498.

17. Kay SR, Fiszbein A, Opler LA. The positive and negative syndrome scale (PANSS) for schizophrenia. Schizophr Bull 1987; 13:261-276.

18. Rummel-Kluge $\mathrm{C}$, Komossa $\mathrm{K}$, Schwarz $\mathrm{S}$, Hunger $\mathrm{H}$, Schmid F, Lobos CA, et al. Head-to-head comparisons of metabolic side effects of second generation antipsychotics in the treatment of schizophrenia: a systematic review and meta-analysis. Schizophr Res 2010;123:225-233.

19. Dayabandara M, Hanwella R, Ratnatunga S, Seneviratne $S$, Suraweera C, de Silva VA. Antipsychotic-associated weight gain: management strategies and impact on treatment adherence. Neuropsychiatr Dis Treat 2017;13:2231-2241.

20. Pascoli V, Terrier J, Hiver A, Lüscher C. Sufficiency of mesolimbic dopamine neuron stimulation for the progression to addiction. Neuron 2015;88:1054-1066.

21. Koob GF, Volkow ND. Neurocircuitry of addiction. Neuropsychopharmacology 2010;35:217-238.

22. Mezquida G, Savulich G, Garcia-Rizo C, Garcia-Portilla MP, Toll A, Garcia-Alvarez L, et al. Inverse association between negative symptoms and body mass index in chronic schizophrenia. Schizophr Res 2018;192:69-74. 